\title{
Conteúdo de nutrientes na serapilheira em três fisionomias do Cerrado do Distrito Federal
}

\author{
Fabiana Piontekowski Ribeiro ${ }^{1 *}$, Angela Pereira Bussinguer ${ }^{1}$, Bárbara Elias Reis Hodecker ${ }^{2}$, Alcides Gatto ${ }^{1}$ \\ ${ }_{1}^{1}$ Universidade de Brasília, Faculdade de Tecnologia, L3 norte, CEP 70910-900, Brasília, DF, Brasil \\ ${ }^{2} U$ nião Pioneira de Integração Social, BR 020, Km 12, DF 335, Km 4,8, CEP 70390-125, Brasília, DF, Brasil
}

"Autor correspondente:
fbn2.ribeiro@gmail.com

Termos para indexação:

Macronutrientes

Micronutrientes

Eucalyptus

Index terms:

Macronutrients

Micronutrients

Eucalyptus

Histórico do artigo:

Recebido em 04/07/2016

Aprovado em 30/11/2017

Publicado em 29/12/2017

doi: 10.4336/2017.pfb.37.92.1312

\begin{abstract}
Resumo - O estudo foi realizado na Fazenda Água Limpa, DF, em três fisionomias: Cerrado típico, mata de galeria e povoamento de Eucalyptus urograndis, e teve por objetivo analisar o conteúdo de macro e micronutrientes via estoque de serapilheira, durante as épocas seca e chuvosa. Procedeu-se a coleta mensal de serapilheira no período de setembro de 2011 a agosto de 2012. As amostras foram coletadas aleatoriamente, com três repetições em cada fisionomia sendo secas para posterior determinação dos teores de nutrientes. Os resultados foram avaliados por análise de variância, teste de Tukey e correlação de Pearson. Os conteúdos de macronutrientes no estoque de serapilheira na Mata de Galeria e eucalipto apresentaram-se na ordem de $\mathrm{N}>\mathrm{Ca}>\mathrm{K}$ $>\mathrm{Mg}>\mathrm{S}>\mathrm{P}$ no período chuvoso, e no seco o $\mathrm{S}$ foi superior ao $\mathrm{Mg}$ para o eucalipto, não sendo observada alteração na Mata de Galeria. No Cerrado típico, a ordem foi $\mathrm{N}$ $>\mathrm{Ca}>\mathrm{S}>\mathrm{Mg}>\mathrm{K}>\mathrm{P}$ no período chuvoso, alterando para $\mathrm{N}>\mathrm{Ca}>\mathrm{K}>\mathrm{S}>\mathrm{Mg}>$ $\mathrm{P}$ no período seco.
\end{abstract}

\section{Litter nutrient content in three different forest formations of Cerrado, Federal District, Brazil}

\begin{abstract}
The study was conducted at Água Limpa Farm, DF, in three vegetation types: Cerrado sensu stricto, Gallery Forest and Eucalyptus urograndis plantation. The aim was to quantify and analyze the macro and micronutrients content presented in the litter stock from these environments during the dry and rainy seasons. The litter samples were collected from September 2011 to August 2012. They were dried and the nutrients content were quantified. The experiment was conducted in a completely randomized design, with three replicates for each treatment. The results were evaluated by analysis of variance, Tukey test and Pearson's correlation. The litter macronutrient content observed at the Gallery Forest and Eucalyptus plantations during the rainy season was in the following order: $\mathrm{N}>\mathrm{Ca}>\mathrm{Mg}>\mathrm{K}>\mathrm{S}>\mathrm{P}$. During the dry season, $\mathrm{S}$ content was higher than $\mathrm{Mg}$ in Eucalyptus plantation, while no differences were observed at the Gallery Forest. Macronutrients contents observed at Cerrado sensu stricto area were $\mathrm{N}>\mathrm{Ca}>\mathrm{S}>\mathrm{Mg}>\mathrm{K}>\mathrm{P}$ in the rainy season and $\mathrm{N}>\mathrm{Ca}>\mathrm{K}>\mathrm{S}>$ $\mathrm{Mg}>\mathrm{P}$ in the dry season.
\end{abstract}

\section{Introdução}

O estabelecimento de plantios florestais e a manutenção das florestas nativas no Brasil tem apresentado elevada importância no contexto atual de produção e conservação ambiental.

Os reflorestamentos para fins industriais no Brasil totalizaram 7,74 milhões de ha em 2014, sendo que desta 
área, 5,56 milhões de ha são ocupados com o plantio de eucalipto, por possuir elevadas taxas de crescimento e permitir obter multiprodutos (Indústria Brasileira de Árvores, 2015), mas por outro lado, apresentam altas taxas de absorção e exportação dos nutrientes adquiridos pelo solo (Laclau et al., 2013; Tang et al., 2013; Versini et al., 2013).

Atualmente, vários estudos têm se concentrado em entender a dinâmica da ciclagem de nutrientes via serapilheira, por sua relevância e elevada influência na manutenção da produtividade vegetal, tanto em plantios, como em florestas naturais de ecossistemas tropicais (Richards et al., 2010; Skorupa et al., 2015). Estudos de processos que regulam as atividades do solo em ecossistemas naturais podem fornecer informações importantes sobre opções de manejo, com a finalidade de manter a fertilidade do solo ao longo do tempo.

Nos plantios florestais, a quantidade de serapilheira e o conteúdo de nutrientes que são naturalmente aportados ao solo refletem a capacidade produtiva e o potencial de recuperação ambiental das plantações, tendo em vista as modificações que ocorrem nas características físicas e químicas do solo e, consequentemente, na dinâmica alimentar resultante da adição do material orgânico ao solo (Viera et al., 2014). Esse aporte tem influência direta na biodiversidade e auxilia o entendimento da dinâmica dos ecossistemas florestais (Alves et al., 2006).

A transferência de nutrientes dos compartimentos arbóreos para o solo ocorre no processo de ciclagem de nutrientes, envolvendo eventos que ocorrem dentro de um ou mais ciclos naturais. Os padrões conceituais desse processo são complexos e constantemente envolvem três componentes fundamentais na movimentação de nutrientes: as plantas, os animais e o solo (Alves et al., 2006).

$\mathrm{O}$ estoque e a qualidade da serapilheira variam em função do material de origem do solo, da espécie vegetal, do tipo de cobertura florestal, do estágio sucessional da floresta e da época de coleta de amostras para avaliação do teor de nutrientes. Adicionalmente, condições edafoclimáticas, regime hídrico, sítio, capacidade produtiva e tipo de material genético, idade, topografia, sub-bosque, manejo silvicultural, tamanho de copa, bem como taxa de deposição e decomposição, distúrbios naturais como fogo e ataque de insetos, ou artificiais, como também remoção da serapilheira e cultivos sucessivos, influenciam no estoque e na qualidade da serapilheira (Vieira et al., 2009, 2013, 2014; Schumacher et al., 2013; Skorupa et al., 2015; Villa et al., 2016).
Cabe ressaltar a influência da precipitação e características das espécies presentes nos ecossistemas, como fatores preponderantes dos aspectos qualitativos, como o conteúdo de nutrientes aportado, e quantitativos, como a massa acumulada de matéria seca da serapilheira (Macedo et al., 2008).

Seja em sistemas naturais ou implantados, o estoque de serapilheira age na manutenção do processo de ciclagem de nutrientes e na sustentabilidade das florestas, por ser capaz de influenciar as propriedades físicas, químicas e biológicas do solo e, inclusive, sobre os processos erosivos, por influir na agregação das partículas do solo e de protegê-lo do impacto direto das gotas de chuva (Campos et al., 2008).

Nesse sentido, o estoque de serapilheira e a quantificação dos nutrientes que retornam ao solo pela decomposição (Richards et al., 2010; Skorupa et al., 2015; Ferreira et al., 2016) é um dos aspectos mais estudados nos sistemas florestais, visto sua importante contribuição na manutenção da ciclagem de nutrientes nestes solos. A partir da hipótese de que cada ambiente possui um aporte diferenciado de armazenamento de nutrientes, o objetivo desse estudo foi quantificar e analisar os conteúdos de macro e micronutrientes no estoque de serapilheira de três fisionomias (Cerrado sensu stricto, mata de galeria e plantio de eucalipto), nas épocas seca e chuvosa, na região do Distrito Federal.

\section{Material e métodos}

O estudo foi conduzido na Fazenda Água Limpa

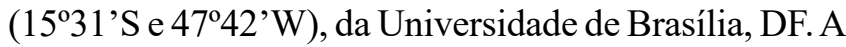
propriedade tem uma área aproximada de 4.340 ha, dos quais 2.340 ha (aproximadamente $54 \%$ da área total) são destinados à preservação, 800 ha à conservação (18\%) e 1.200 ha (28\%) à produção agropecuária e florestal.

O clima da região é do tipo Aw, segundo a classificação de Köppen, com duas estações climáticas bem definidas: seca, entre os meses de maio a setembro, e chuvosa, entre outubro e abril. Durante o período de estudo, a temperatura média observada foi de 19,9 ${ }^{\circ} \mathrm{C}$, e a precipitação média total anual correspondeu a 1766,2 $\mathrm{mm}$ (Figura 1), de acordo com os dados obtidos na Estação Meteorológica Experimental de Agroclimatologia, instalada na Fazenda Água Limpa. Os solos das três áreas de estudo foram classificados como Latossolo Vermelho-Amarelo distrófico típico, de textura argilosa (Santos et al., 2013). 


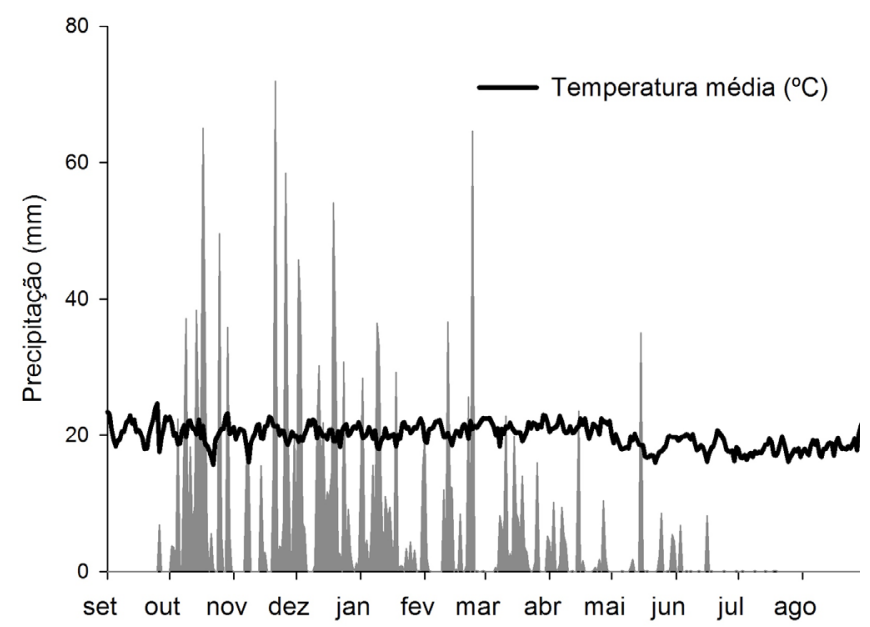

Figura 1. Variação mensal da pluviosidade $(\mathrm{mm})$ e temperatura do ar $\left({ }^{\circ} \mathrm{C}\right)$ entre setembro de 2011 e agosto de 2012, na Fazenda Água Limpa, DF.

O estudo foi realizado em áreas de Cerrado sensu stricto $(\mathrm{CT})$, mata de galeria $(\mathrm{MG})$ e um povoamento de eucalipto (EU), implantado em dezembro de 2005 com o clone GG100 obtido de híbrido de Eucalyptus urophylla x Eucalyptus grandis, no espaçamento de $3 \mathrm{~m}$ x $2 \mathrm{~m}$. O preparo reduzido do solo consistiu na subsolagem a $70 \mathrm{~cm}$ de profundidade, com a incorporação de $500 \mathrm{~kg}$ ha $^{-1}$ de superfosfato simples e $280 \mathrm{~g}$ planta $^{-1}$ de NPK na mistura granulada 20-5-20, mais 1,4 g planta $^{-1}$ de B e Zn, com a primeira aplicação com 15 dias após o plantio; e a segunda, no início da época chuvosa. A área de CT passou por um incêndio durante a época seca de 2011. Esse evento não interferiu na sobrevivência das plantas existentes no local, mas consumiu parte da serapilheira depositada sobre o solo. Vale ressaltar que todas as coletas nessa área foram realizadas posteriormente à ocorrência deste evento natural, sendo evitadas as áreas mais atacadas pelo fogo.

Em cada área de estudo, foi feita coleta mensal de serapilheira, durante o período de setembro de 2011 a agosto de 2012, mediante amostragem aleatória com três repetições, onde cada ponto amostral obedeceu a um limite mínimo de $5 \mathrm{~m}$ de distância entre os demais pontos amostrais. Para a coleta, utilizou-se um gabarito metálico com dimensão de $0,5 \mathrm{~m}$ x $0,5 \mathrm{~m}$. As coletas foram realizadas em locais com condições topográficas semelhantes e a um limite de $20 \mathrm{~m}$ de estradas e aceiros, com a finalidade de evitar efeito de borda.
A serapilheira coletada foi acondicionada e identificada em embalagens de papel e posteriormente secas em estufa de circulação forçada de ar a $65^{\circ} \mathrm{C}$, por um período mínimo de $72 \mathrm{~h}$, até a obtenção de massa constante. Em seguida, as amostras de serapilheira foram pesadas, moídas e analisadas quimicamente quanto aos teores de macro e micronutrientes. Para determinação do N, foi realizada a digestão sulfúrica, seguida de determinação pelo método Kjeldahl e o $\mathrm{S}$ foi determinado por turbidimetria. As amostras foram submetidas à digestão nitroperclórica para a determinação dos teores de $\mathrm{Ca}, \mathrm{Mg}$, $\mathrm{P}, \mathrm{K}, \mathrm{S}, \mathrm{Fe}, \mathrm{Zn}, \mathrm{Cu}$ e $\mathrm{Mn}$. O P e S foram determinados em espectrofotômetro de absorção molecular, o K por fotometria com emissão de chama, e $\mathrm{Ca}, \mathrm{Mg}, \mathrm{Fe}, \mathrm{Zn}$, $\mathrm{Cu}$ e $\mathrm{Mn}$ por espectrofotômetro de absorção atômica. Para o B utilizou-se mufla a $600{ }^{\circ} \mathrm{C}$ e determinação em espectrofotômetro, pelo método da Azometina $\mathrm{H}^{+}$ (Wolf, 1974).

A análise estatística dos tratamentos foi realizada pela análise de variância (ANOVA). Posteriormente, foi realizada a comparação das médias pelo teste de Tukey a $5 \%$ de significância. Todas as análises foram realizadas com o software Statistica versão 8.0. Para avaliar a correlação entre os teores de macro e micronutrientes e estoque de serapilheira foi realizada a análise de correlação Pearson.

\section{Resultados e discussão}

\section{Estoque de serapilheira}

Os dados coletados mostram que o estoque de serapilheira não variou nas estações seca e chuvosa em cada uma das fisionomias estudadas. Na época chuvosa, a mata de galeria (MG) apresentou aproximadamente duas vezes o estoque observado no Cerrado sensu strictu (CT) (Tabela 1), resultado diferente daquele obtido por Parron et al. (2004), que observaram maior deposição de serapilheira em MG durante a época seca. No entanto, estão consistentes com avaliações realizadas na mesma região do presente estudo por Souza et al. (2016).

$\mathrm{O}$ menor estoque de serapilheira observado para o $\mathrm{CT}$, na época chuvosa pode estar relacionado à própria formação florestal, caracterizada por diversos níveis de caducifólia durante a época seca, sendo que nos demais meses do ano, pouco material é depositado sob os solos (Ribeiro \& Walter, 2008). 
Tabela 1. Estoque de serapilheira e conteúdo de macronutrientes em três fisionomias no Cerrado na Fazenda Água Limpa, DF.

\begin{tabular}{|c|c|c|c|c|c|c|c|}
\hline \multirow{3}{*}{ Fisionomias } & Serapilheira & $\mathrm{N}$ & $\mathrm{P}$ & $\mathrm{K}$ & $\mathrm{Ca}$ & $\mathrm{Mg}$ & $\mathrm{S}$ \\
\hline & \multicolumn{7}{|c|}{ 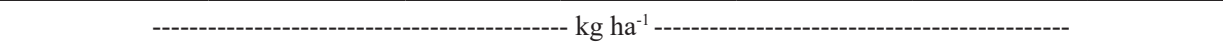 } \\
\hline & \multicolumn{7}{|c|}{ Época chuvosa } \\
\hline $\mathrm{CT}$ & $4.992,46 \mathrm{bA}$ & $47,41 \mathrm{cB}$ & $1,54 \mathrm{bA}$ & $4,15 \mathrm{bB}$ & $17,73 \mathrm{bB}$ & $4,69 \mathrm{bB}$ & $7,0 \mathrm{aB}$ \\
\hline MG & $10.262,25 \mathrm{aA}$ & $123,18 \mathrm{aA}$ & $5,32 \mathrm{aA}$ & $11,77 \mathrm{aA}$ & $43,47 \mathrm{aA}$ & $10,99 \mathrm{aA}$ & $7,96 \mathrm{aA}$ \\
\hline \multirow[t]{2}{*}{$\mathrm{EU}$} & $8.372,11 \mathrm{aA}$ & $74,39 \mathrm{bA}$ & $3,65 \mathrm{aA}$ & $10,16 \mathrm{aB}$ & $45,59 \mathrm{aA}$ & $9,69 \mathrm{aA}$ & $9,18 \mathrm{aA}$ \\
\hline & \multicolumn{7}{|c|}{ Época seca } \\
\hline $\mathrm{CT}$ & $7.610,4 \mathrm{aA}$ & $58,62 \mathrm{aA}$ & $2,43 \mathrm{bA}$ & $17,43 \mathrm{aA}$ & $27,96 \mathrm{aA}$ & $8,53 \mathrm{aA}$ & $15,95 \mathrm{aA}$ \\
\hline MG & $8.107,56 \mathrm{aA}$ & $102,92 \mathrm{aB}$ & $4,95 \mathrm{aA}$ & $14,53 \mathrm{aA}$ & $47,79 \mathrm{aA}$ & $9,46 \mathrm{aA}$ & $7,95 \mathrm{bA}$ \\
\hline EU & $10.175,27 \mathrm{aA}$ & $90,59 \mathrm{aA}$ & $5,56 \mathrm{aA}$ & $26,69 \mathrm{aA}$ & $48,37 \mathrm{aA}$ & $11,98 \mathrm{aA}$ & $12,77 \mathrm{bA}$ \\
\hline
\end{tabular}

$\mathrm{CT}=$ Cerrado sensu stricto $; \mathrm{MG}=$ mata de galeria; $\mathrm{EU}=$ plantio de eucalipto. Letras minúsculas diferentes indicam diferença de médias entre as fisionomias em cada época; e letras maiúsculas diferentes, indicam diferenças de médias entre a época chuvosa e a seca do ano para a mesma fisionomia, ambos a 5\% de probabilidade pelo teste Tukey.

Além da influência da queimada na região, que pode ter consumido parte do material depositado, comparativamente à $\mathrm{MG}$, os $\mathrm{CT}$ possuem menor densidade vegetal, menor estratificação arbórea e, consequentemente, menor cobertura arbórea (Ribeiro \& Walter, 2008), influenciando diretamente em maiores taxas de deposição de material foliar em MG.

$\mathrm{O}$ estoque médio de serapilheira observado na área de CT no presente estudo apresentou valor próximo ao verificado em uma área de $\mathrm{CT}$ em Curvelo, MG (6,46 $\mathrm{t} \mathrm{ha}^{-1}$ ) (Paiva et al., 2011), apesar de inferior à área de CT em Brasília, DF (média de 7,11 t ha-1) (Ribeiro et al., 2011).

O Cerrado evolui com a ocorrência de queimadas naturais e, portanto, a flora é adaptada a esse evento. Os incêndios tendem a ocorrer na época seca, quando há maior deposição de serapilheira e menor taxa de decomposição desta, e sua intensidade e abrangência dependem do material combustível. Além disso, as atividades reprodutivas da maioria das espécies do Cerrado ocorrem na época chuvosa, não sendo prejudicadas por queimadas estacionais a intervalos longos (Felfili et al., 2000). Desta forma, o estoque de serapilheira pode ter sido influenciado no presente trabalho pela queimada natural ocorrida na área de CT.

$\mathrm{O}$ estoque médio anual de serapilheira verificado no plantio de eucalipto (EU) $\left(9.272,69 \mathrm{~kg} \mathrm{ha}^{-1} \mathrm{ano}^{-1}\right)$, foi inferior ao comparado com estudos realizados por Melos et al. (2010), Gatto et al. (2014) e Souza et al. (2016) e superior aos de Cunha et al. (2005), Cunha Neto et al. (2013) e Santos et al. (2017). No caso de povoamentos florestais, as diferenças entres os estoques de serapilheira podem ser atribuídas à densidade de plantio e espaçamento do povoamento (Villa et al., 2016), idade das árvores (Corrêa et al., 2016), tipo de clone (Conti Júnior et al., 2017), condições climáticas (Carvalho et al., 2017) e qualidade química do solo (Gatto et al., 2014).

\section{Conteúdo de macronutrientes na serapilheira}

O conteúdo de macronutrientes variou entre as épocas do ano, principalmente para o ambiente $\mathrm{CT}$, onde foram observados maiores teores de N, Ca, K, S e Mg na época seca (Tabela 1). Ao estudarem nutrientes foliares de algumas espécies de CT em diferentes épocas do ano, Rossatto et al. (2013) encontraram resultados diferentes dos observados no presente estudo, com as maiores concentrações observadas na época chuvosa, para N, K, $\mathrm{Ca}, \mathrm{Mg}$ e $\mathrm{P}$. Tais diferenças podem ser explicadas pela diferença de composição florística, com possibilidade de presença de espécies com demandas nutricionais distintas, resultando em absorção, translocação e deposição ao solo diferenciadas.

Para a MG o teor de $\mathrm{N}$ foi superior na época chuvosa (Tabela 1). Esse elemento tem grande relação com a matéria orgânica, que é favorecida em fisionomias de MG por apresentar grande heterogeneidade de espécies florestais e por se localizarem no fundo de vales próximo a cursos de água. Nos plantios de EU o teor de K foi superior na época seca (Tabela 1). Esse elemento é retranslocado, apresentando grande mobilidade, sendo que na época chuvosa tende a ser mais lixiviado.

De maneira geral, na época chuvosa, foram observadas diferenças entre o conteúdo de macronutrientes nas 
fisionomias estudadas. Os conteúdos de N, P, K, Ca e $\mathrm{Mg}$ presentes na serapilheira do CT foram inferiores aos observados na MG e EU (Tabela 1). O baixo conteúdo de nutrientes na serapilheira da fisionomia CT pode está relacionado aos reduzidos teores de nutrientes presentes nos solos do Cerrado, ambiente savânico (Lloyd et al., 2008; Paoli et al., 2008; Viani et al., 2011; Vourlitis et al., 2013). Além disso, deve-se levar em conta a questão da estratégia evolutiva relacionada à ciclagem interna e/ ou mobilização de nutrientes que antecede a deiscência das folhas (Haridasan, 2001; Prado et al., 2004; Franco, 2005; Nardoto et al., 2006).

$\mathrm{Na}$ época seca, os conteúdos de macronutrientes não diferiram entre as fisionomias estudadas, exceto para $\mathrm{CT}$ que apresentou menor conteúdo de $\mathrm{P}$ e maior de $\mathrm{S}$ (Tabela 1). Na área de CT a baixa concentração de $\mathrm{P}$, associada à elevada translocação interna deste nutriente para os tecidos jovens em formação, reduz seu conteúdo nos tecidos em processo de senescência, o que reflete na baixa concentração desse elemento na serapilheira. Para o $\mathrm{S}$ foi observado comportamento oposto, visto que este nutriente possui baixa remobilização interna (Hawkesford et al., 2012), levando a maiores teores nas folhas mais velhas e em processo de senescência, o que refletiu no incremento do conteúdo deste na serapilheira na área de CT.

Os conteúdos de nutrientes encontrados na serapilheira foram maiores para o $\mathrm{N}$, seguido de $\mathrm{Ca}$, e menores para $\mathrm{P}$ (Tabela 1). $\mathrm{O}$ elevado conteúdo de $\mathrm{N}$ pode ser devido à elevada demanda nutricional deste elemento sem reaproveitamento em outras partes da planta, uma vez que este é altamente móvel e facilmente retranslocado dos tecidos mais velhos para os mais jovens, concentrandose principalmente nas folhas. Entretanto, cabe ressaltar que nem todo $\mathrm{N}$ é retranslocado na planta e, devido ao seu alto requerimento pelas plantas em todos os estágios de crescimento, associado à maior parte da serapilheira ser formada praticamente por tecidos deiscentes, esta apresenta elevados conteúdos deste elemento (Cantarella, 2007).

Para EU, o $\mathrm{N}$ também foi o elemento mais representativo, seguido pelo $\mathrm{Ca}, \mathrm{K}$ e $\mathrm{Mg}$. No entanto, Viera et al. (2013) encontram Ca em maior proporção que $\mathrm{N}$ na serapilheira em um povoamento de Eucalyptus urophylla x Eucalyptus globulus. Isso pode ter relação com a idade do povoamento, que era 2 anos mais velho e, por sua vez, tinha produzido mais cascas. Nesse sentido, quanto mais velho e senescente for o material vegetal, maior será o teor relativo de Ca (Turner \& Lambert, 2016).

Independente da fisionomia, o fato do $\mathrm{Ca}$ ter apresentado o segundo maior conteúdo na serapilheira estocada pode estar relacionado à sua baixa mobilidade nos tecidos vegetais, resultante de sua função na estruturação das cadeias pécticas presentes na parede celular (Hawkesford et al., 2012) e também com a longevidade das folhas. Aliado à sua baixa mobilidade no interior dos tecidos vegetais, esse elemento é tido como um dos fatores determinantes para que a sua maior ciclagem no ambiente aconteça pela queda e decomposição dos tecidos vegetais senescentes (Caldeira et al., 2007).

Menores conteúdos de $\mathrm{P}$, comparado aos demais nutrientes, foram observados nas três fisionomias avaliadas. Os solos tropicais apresentam naturalmente baixos teores de $\mathrm{P}$ mineral e mesmo quando ocorre entrada desse elemento via adubação, apresenta baixa taxa de recuperação pelas plantas, decorrente da complexidade físico-química, tais como: adsorção, fixação e precipitação, tornando o $P$ pouco lábil (Novais et al., 2007). Cabe ressaltar que o P é um dos elementos que possuem alta taxa de translocação interna nas plantas (Sanchez, 2006).

O conteúdo total de nutrientes na serapilheira reflete a concentração dos elementos nos tecidos vegetais e na quantidade de liteira produzida (Bündchen et al., 2013). Por isso, as fisionomias apresentam diferenças nos conteúdos de macronutrientes, devido à variabilidade na concentração e na produção de biomassa vegetal dos diversos ecossistemas. Apesar disso, a serapilheira é a fonte principal de transferência de N, Ca e Mg para o solo (Caldeira et al., 2007, 2013), e também de P, já que mais de $90 \%$ da transferência desse elemento é de origem orgânica (Novais et al., 2007).

Na fisionomia EU as correlações da serrapilheira com o conteúdo de $\mathrm{N}$ e $\mathrm{P}$ foram negativas em ambas as estações do ano, não explicando nenhum comportamento quanto à sazonalidade (Tabela 2). Na fisionomia MG, a correlação positiva de $\mathrm{K}(0,83)$ com a época chuvosa (Tabela 2$)$, indica que aumentando as chuvas há incremento de $\mathrm{K}$ na serapilheira, reflexo da maior absorção do elemento (fluxo de massa) e consequente crescimento da planta. $\mathrm{Na}$ fisionomia $\mathrm{CT}$ o $\mathrm{N}$ teve correlação positiva na época seca, provavelmente porque a taxa de deposição de material vegetal foi intensificada nessa época. 
Tabela 2. Coeficientes de correlação de Pearson dos teores macronutrientes nas estações chuvosa e seca.

\begin{tabular}{|c|c|c|c|c|c|c|}
\hline Fisionomia & $\mathrm{N}$ & $\mathrm{P}$ & $\mathrm{K}$ & $\mathrm{Ca}$ & $\mathrm{Mg}$ & S \\
\hline & \multicolumn{6}{|c|}{ Época chuvosa } \\
\hline Cerrado típico & $0,43^{\mathrm{ns}}$ & $-0,38^{\mathrm{ns}}$ & $-0,69^{\text {ns }}$ & $-0,55^{\text {ns }}$ & $-0,50^{\mathrm{ns}}$ & $0,08^{\text {ns }}$ \\
\hline Mata de galeria & $-0,37^{\mathrm{ns}}$ & $-0,24^{\mathrm{ns}}$ & $0,83 *$ & $-0,03^{\text {ns }}$ & $-0,27^{\mathrm{ns}}$ & $0,52^{\text {ns }}$ \\
\hline \multirow[t]{2}{*}{ Eucalipto } & $-0,84^{*}$ & $-0,73^{*}$ & $-0,08^{\mathrm{ns}}$ & $0,72^{\text {ns }}$ & $0,74^{\mathrm{ns}}$ & $0,08^{\text {ns }}$ \\
\hline & \multicolumn{6}{|c|}{ Época seca } \\
\hline Cerrado típico & $0,87^{*}$ & $0,47^{\mathrm{ns}}$ & $-0,74^{\mathrm{ns}}$ & $0,50^{\mathrm{ns}}$ & $-0,18^{\mathrm{ns}}$ & $-0,12^{\mathrm{ns}}$ \\
\hline Mata de galeria & $0,46^{\mathrm{ns}}$ & $0,38^{\text {ns }}$ & $-0,73^{\text {ns }}$ & $-0,40^{\text {ns }}$ & $-0,37^{\mathrm{ns}}$ & $0,41^{\mathrm{ns}}$ \\
\hline Eucalipto & $-0,93 * *$ & $-0,74^{\mathrm{ns}}$ & $0,45^{\mathrm{ns}}$ & $-0,11^{\mathrm{ns}}$ & $0,66^{\mathrm{ns}}$ & $0,22^{\text {ns }}$ \\
\hline
\end{tabular}

ns = não significativo, * significativo a $5 \% ; * *$ significativo a $1 \%$

\section{Conteúdo de micronutrientes}

Ao avaliar o comportamento e conteúdo de micronutrientes em relação à sazonalidade, foram observadas diferenças significativas entre as épocas do ano para $\mathrm{B}$, que foi superior na fisionomia EU durante a época seca. $\mathrm{Cu}, \mathrm{Mn}$ e $\mathrm{Zn}$ foram superiores na $\mathrm{MG}$ na época chuvosa (Tabela 3 ). $\mathrm{O}$ incremento de $\mathrm{B}$, observado na serapilheira do EU na época seca, pode ser resultante de sua menor mobilidade nos tecidos vegetais (Raven, 1980) e por ser constituinte das moléculas de ramnogalacturonanos II (O'neill et al., 2004), presentes na pectina que é o maior componente da parede primária vegetal (Matoh et al., 1996).

O conteúdo de $\mathrm{Cu}, \mathrm{Mn}$ e $\mathrm{Zn}$ também foram superiores na fisionomia $\mathrm{MG}$, quando comparado às demais fisionomias na época chuvosa. Na época seca, o Mn e o $\mathrm{Zn}$ permaneceram superiores. Isso pode ser resultado do $\mathrm{pH}(5,0-6,5)$ dos solos da região, que estão em uma faixa onde esses micronutrientes ficam mais disponíveis para as plantas.

Dentre os micronutrientes, o maior conteúdo foi observado para o Fe, seguido de $\mathrm{Mn}$, em todas as fisionomias estudadas (Tabela 3), o que pode ser explicado em parte devido à sua maior concentração em relação aos demais nutrientes nos tecidos vegetais, consequência da alta abundância destes na litosfera (Abreu et al., 2007). Entre as áreas estudadas, o conteúdo de Fe foi superior nas fisionomias CT e EU, independente da época do ano (Tabela 3).

As fisionomias MG e CT mantiveram a mesma ordem de magnitude $(\mathrm{Fe}>\mathrm{Mn}>\mathrm{Zn}>\mathrm{B}>\mathrm{Cu}$ ) para época chuvosa e seca, e no EU o conteúdo de $\mathrm{B}$ foi superior ao $\mathrm{Zn}$. Tal diferença pode ser explicada pelo fato de cada espécie ou conjunto de espécies ter uma habilidade diferenciada para a absorção de um ou outro nutriente e, além disso, por vezes na mesma espécie ocorre grande diferenciação quanto à eficiência de absorção e utilização de nutrientes (Barros et al., 1990), como exemplificado por trabalho realizado por Silveira et al. (2002), onde encontraram diferenças quanto à eficiência de uso de B para produção de matéria seca total entre clones de Eucalyptus.

Analisando as correlações de Pearson entre os valores de estoque da serapilheira em relação à disponibilidade dos teores de micronutrientes, observou-se que houve correlação significativa apenas para a fisionomia $\mathrm{CT}$ para o $\mathrm{B}(0,92)$ na época chuvosa, e Fe na época seca $(0,83)$ (Tabela 4). Durante a época chuvosa, com aumento da disponibilidade hídrica, há maior absorção de B pelas plantas, devido ao incremento da taxa da transpiração vegetal (Mattiello et al., 2009).

Na avaliação dos conteúdos de macro e micronutrientes não foram observadas correlações em relação à sazonalidade e estoque de serapilheira (Tabelas 2 e 4), o que pode evidenciar que a disponibilidade destes nutrientes está relacionada a outros fatores, como taxa de crescimento das plantas, estrutura da vegetação e, principalmente, ao fato dos solos do Cerrado serem naturalmente ácidos e distróficos, e apresentarem baixa disponibilidade de nutrientes (Haridasan, 2008). Fator esse confirmado por outros autores, que observaram a influência da baixa disponibilidade de nutrientes em formações savânicas na qualidade e estoque da serapilheira (Paoli et al., 2008; Viani et al., 2011; Vourlitis et al., 2013). 
Tabela 3. Conteúdo de micronutrientes da serapilheira em três fisionomias no Cerrado na Fazenda Água Limpa, DF.

\begin{tabular}{|c|c|c|c|c|c|}
\hline \multirow{2}{*}{ Fisionomias } & B & $\mathbf{C u}$ & $\mathbf{F e}$ & Mn & $\mathbf{Z n}$ \\
\hline & \multicolumn{5}{|c|}{ 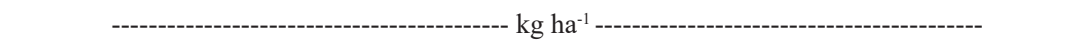 } \\
\hline & \multicolumn{5}{|c|}{ Época chuvosa } \\
\hline CT & $0,09 \mathrm{bA}$ & $0,04 \mathrm{bA}$ & $45,34 \mathrm{aA}$ & $1,18 \mathrm{bA}$ & $0,11 \mathrm{bA}$ \\
\hline MG & $0,15 \mathrm{bA}$ & 0,06 aA & $14,16 \mathrm{bA}$ & $3,83 \mathrm{aA}$ & $0,24 \mathrm{aA}$ \\
\hline \multirow[t]{2}{*}{ EU } & $0,23 \mathrm{aB}$ & $0,03 \mathrm{bA}$ & $38,07 \mathrm{aA}$ & $1,73 \mathrm{bA}$ & $0,09 \mathrm{bA}$ \\
\hline & \multicolumn{5}{|c|}{ Época seca } \\
\hline $\mathrm{CT}$ & $0,10 \mathrm{bA}$ & $0,05 \mathrm{aA}$ & $53,01 \mathrm{aA}$ & $1,38 \mathrm{bA}$ & $0,13 \mathrm{bA}$ \\
\hline MG & $0,12 \mathrm{bA}$ & $0,05 \mathrm{aB}$ & $11,59 \mathrm{bA}$ & $3,14 \mathrm{aB}$ & $0,19 \mathrm{aB}$ \\
\hline EU & $0,28 \mathrm{aA}$ & $0,03 \mathrm{aA}$ & $45,03 \mathrm{aA}$ & $2,05 \mathrm{bA}$ & $0,11 \mathrm{bA}$ \\
\hline
\end{tabular}

$\overline{\mathrm{CT}}=$ Cerrado sensu stricto $\mathrm{MG}=$ mata de galeria; $\mathrm{EU}=$ plantio de eucalipto. Letras minúsculas diferentes indicam diferença de médias entre as fisionomias em cada época; e letras maiúsculas diferentes, indicam diferenças de médias entre a época chuvosa e a seca do ano para a mesma fisionomia, ambos a $5 \%$ de probabilidade pelo teste Tukey.

Tabela 4. Coeficientes de correlação de Pearson dos teores de micronutrientes nas estações chuvosa e seca.

\begin{tabular}{|c|c|c|c|c|c|}
\hline Fisionomia & B & $\mathrm{Cu}$ & $\mathbf{F e}$ & Mn & Zn \\
\hline & \multicolumn{5}{|c|}{ Estação chuvosa } \\
\hline Cerrado Típico & $0,92 * *$ & $-0,04^{\mathrm{ns}}$ & $-0,19^{\text {ns }}$ & $0,37^{\mathrm{ns}}$ & $-0,23^{\mathrm{ns}}$ \\
\hline Mata de Galeria & $-0,32^{\text {ns }}$ & $-0,02^{\text {ns }}$ & $0,49^{\text {ns }}$ & $0,45^{\mathrm{ns}}$ & $0,02^{\text {ns }}$ \\
\hline \multirow[t]{2}{*}{ Eucalipto } & $0,21^{\mathrm{ns}}$ & $-0,20^{\text {ns }}$ & $0,13^{\text {ns }}$ & $0,08^{\text {ns }}$ & $-0,61^{\mathrm{ns}}$ \\
\hline & \multicolumn{5}{|c|}{ Estação seca } \\
\hline Cerrado Típico & $0,45^{\mathrm{ns}}$ & $0,14^{\mathrm{ns}}$ & $-0,83^{*}$ & $-0,08^{\mathrm{ns}}$ & $-0,18^{\mathrm{ns}}$ \\
\hline Mata de Galeria & $-0,66^{\mathrm{ns}}$ & $0,70^{\mathrm{ns}}$ & $-0,21^{\mathrm{ns}}$ & $-0,31^{\mathrm{ns}}$ & $-0,30^{\mathrm{ns}}$ \\
\hline Eucalipto & $-0,68^{\text {ns }}$ & $0,40^{\mathrm{ns}}$ & $0,18^{\mathrm{ns}}$ & $-0,17^{\mathrm{ns}}$ & $0,18^{\text {ns }}$ \\
\hline
\end{tabular}

ns $=$ não significativo, $*$ significativo a $5 \% ; *$ significativo a $1 \%$.

No caso das florestas plantadas, há evidências de que a exportação da biomassa resultante da alta intensidade da colheita, manejo florestal, e até mesmo histórico da área, pode influenciar na quantidade dos nutrientes aportados (Gatto et al., 2014). Em florestas nativas, essa disponibilidade pode estar relacionada com a interação e composição das espécies nestes sistemas (Lloyd et al., 2008).

\section{Conclusões}

Os nutrientes $\mathrm{N}$ e $\mathrm{Fe}$ apresentam as maiores proporções no conteúdo da serapilheira, comparado aos demais nutrientes, independente da fisionomia e época do ano avaliada.
A sazonalidade influenciou principalmente as fisionomias de vegetação nativa, que apresentaram maiores conteúdos de macronutrientes na época seca para o Cerrado sensu strictu e maiores de micronutrientes na época chuvosa para a mata de galeria.

\section{Referências}

Abreu, C. A. et al. Micronutrientes. In: Novais, R. F. et al. Fertilidade do solo. Viçosa, MG: Sociedade Brasileira de Ciência do Solo, 2007. p. 646-736.

Alves, A. R. et al. Aporte e decomposição de serapilheira em área de Caatinga, na Paraíba. Revista de Biologia e Ciências da Terra, v. 6, n. 2, p. 194-203, 2006.

Barros, N. F. et al. Fertilização e correção do solo para o plantio de eucalipto. In: Barros, N. F. \& Novais, R. F. (Ed.). Relação soloeucalipto. Viçosa, MG: Folha de Viçosa, 1990. p. 127-186. 
Bündchen, M. et al. Status nutricional e eficiência no uso de nutrientes em espécies arbóreas da floresta subtropical no sul do Brasil. Scientia Forestalis, v. 41, n. 2, p. 227-236, 2013

Caldeira, M. V. W. et al. Biomassa e nutrientes da serapilheira em diferentes coberturas florestais. Comunicata Scientiae, v. 4, n. 2, p. 111-119, 2013.

Caldeira, M. V. W. et al. Quantificação de serapilheira e de nutrientes floresta ombrófila mista Montana - Paraná. Revista Acadêmica, v. 5, n. 2, p. 101-116, 2007.

Campos, E. H. et al. Acúmulo de serrapilheira em fragmentos de Mata Mesofítica e Cerrado stricto senso em Uberlândia-MG. Sociedade \& Natureza, v. 20, n. 1, p. 189-203, 2008.

Cantarella, H. Nitrogênio. In: Novais, R. F. et al. Fertilidade do solo. Viçosa, MG: Sociedade Brasileira de Ciência do Solo, 2007. p. $375-470$.

Carvalho, D. C. et al. Ciclagem de nutrientes de um plantio de eucalipto em regeneração de espécies nativas no sub-bosque. Floresta, v. 47, n. 1, p. 17-27, 2017. DOI: 10.5380/rf.v47i1.43652.

Conti Júnior, J. L. F. et al. Deposição de folhedo e fluxo de nutrientes em eucalipto geneticamente modificado. Brazilian. Pesquisa Florestal Brasileira, v. 37, n. 89, p. 89-92, 2017. DOI: 10.4336/2017. pfb.37.89.985.

Corrêa, R. S. et al. Deposição de serapilheira e micronutrientes ao longo das estações do ano em um plantio de eucalipto estabelecido sobre pastagem natural degradada no bioma pampa. Scientia Forestalis, v. 44, n. 110, p. 435-442, 2016. DOI: 10.18671/scifor. v44n110.16.

Cunha, G. M. et al. Ciclagem de nutrientes em Eucalyptus grandis W. Hill ex Maiden no Norte Fluminense. Revista Árvore, v. 29, n. 3, p. 353-363, 2005. DOI: 10.1590/S0100-67622005000300002.

Cunha Neto, F. et al. Acúmulo e decomposição da serapilheira em quatro formações florestais. Ciência Florestal, v. 23, n. 3, p. 379387, 2013. DOI: 10.5902/1980509810549.

Felfili, J. M. et al. Changes in floristic composition of cerrado sensu stricto in Brazil over a nine-year period. Journal of Tropical Ecology, v. 16, p. 579-590, 2000.

Ferreira, G. W. D. et al. Nutrient release from decomposing Eucalyptus harvest residues following simulated management practices in multiple sites in Brazil. Forest Ecology and Management, v. 370, p. 1-11, 2016. DOI: 10.1016/j.foreco.2016.03.047.

Franco, A. C. Biodiversidade de forma e função: implicações ecofisiológicas das estratégias de utilização de água e luz em plantas lenhosas do cerrado. In: Scariot, A. et al. (Ed.). Cerrado: ecologia, biodiversidade e conservação. Brasília, DF: Ministério de Meio Ambiente, 2005. p. 179-196.

Gatto, A. et al. Ciclagem e balanço de nutrientes no sistema soloplanta em um plantio de Eucalyptus sp. no Distrito Federal. Revista Brasileira de Ciência do Solo, v. 38, p. 879-887, 2014. DOI: 10.1590/S0100-06832014000300019.

Haridasan, M. Nutrient cycling as a function of landscape and biotic characteristics in the cerrado of central Brazil. In: McClain, M. E. et al. (Ed.). Biogeochemistry of the Amazon basin and its role in a changing world. New York: Oxford University Press, 2001. p. 68-83.
Haridasan, M. Nutritional adaptations of native plants of the Cerrado biome in acid soils. Brazilian Journal of Plant Physiology, v. 20, n. 3, p. $183-195$, 2008. DOI: 10.1590/S1677-04202008000300003.

Hawkesford, M. et al. Functions of macronutrients. In: Marschner, P. (Ed.). Marschner's mineral nutrition of higher plants. 3rd ed. Oxford: Elsevier, 2012. p. 135-189.

Indústria Brasileira de Árvores. IBÁ 2015. São Paulo, 2015. 80 p. Relatório Ibá 2015. Disponível em: <http://iba.org/images/shared/ iba_2015.pdf $>$. Acesso em: 9 mar. 2015.

Laclau, J. et al. Mixing Eucalyptus and Acacia trees leads to fine root over-yielding and vertical segregation between species. Oecologia, v. 172, p. 903-913, 2013. DOI: 10.1007/s00442-012-2526-2.

Lloyd, J. et al. Contributions of woody and herbaceous vegetation to tropical savanna ecosystem productivity: a quasi-global estimate. Tree Physiology, v. 28, p. 451-468, 2008.

Macedo, M. O. et al. Changes in soil C and N stocks and nutrient dynamics 13 years after recovery of degraded land using leguminous nitrogen-fixing trees. Forest Ecology and Management, v. 255, p. 1516-1524, 2008. DOI: 10.1016/j.foreco.2007.11.007.

Matoh, T. et al. Ubiquity of a borate-rhamnogalacturonan II complex in the cell walls of higher plants. Plant Cell Physiology, v. 37, p. 636-640, 1996.

Mattiello, E. M. et al. Transporte de Boro no solo e sua absorção. Revista Brasileira de Ciência do Solo, v. 33, p. 1281-1290, 2009.

Melos, A. R. et al. Produção, estoque e retenção hídrica da serrapilheira em encosta sob plantio de híbridos de Eucalyptus Urophylla e Eucalyptus Grandis: médio vale do Rio Paraíba do Sul. Anuário do Instituto de Geociências, v. 3, p. 66-73, 2010.

Nardoto, G. B. et al. Nutrient use efficiency at ecosystem and species level in savanna areas of Central Brazil and impacts of fire. Journal of Tropical Ecology, v. 22, p. 191-201, 2006. DOI: 10.1017/ S0266467405002865.

Novais, R. F. et al. Fósforo. In: Novais, R. F. et al. Fertilidade do solo. Viçosa, MG: Sociedade Brasileira de Ciência do Solo, 2007. p. 471-537.

O'neill, M. A. et al. Rhamnogalacturonan II: structure and function of a borate cross-linked cell wall pectic polysaccharide. Annual Review of Plant Biology, v. 55, p. 109-39, 2004. DOI: 10.1146/ annurev.arplant.55.031903.141750.

Paiva, A. O. et al. Estoque de carbono em Cerrado sensu stricto do Distrito Federal Revista Árvore, v. 35, p. 527-538, 2011. DOI: 10.1590/S0100-67622011000300015.

Paoli, G. D. et al. Soil nutrients affectspatial patterns of aboveground biomass and emergent treedensity in southwestern Borneo. Oecologia, v. 155 , p. $287-299$, 2008. DOI: $10.1007 / \mathrm{s} 00442-007-$ 0906-9.

Prado, C. H. B. A. et al. Seasonal leaf gas exchange and water potential in a woody cerrado species community. Brazilian Journal of Plant Physiology, v. 16, p. 7-16, 2004. DOI: 10.1590/S167704202004000100002.

Parron, L. M. et al. Produção e composição química da serapilheira em um gradiente topográfico em Mata de Galeria no Bioma Cerrado. Planaltina, DF: Embrapa Cerrados, 2004. 23 p. (Embrapa Cerrados. Boletim de pesquisa e desenvolvimento, 128). 
Raven, J. A. Short and long-distance transport of boric acid in plants. New Phytologist, v. 84, p. 231-249, 1980. DOI: 10.1111/j.14698137.1980.tb04424.x.

Ribeiro, J. F \& Walter, B. M. T. As principais fitofisionomias do Bioma Cerrado In: Sano, M. S. \& Almeida, S. P. Cerrado: ecologia e flora. Embrapa: Brasília, DF, 2008. p. 153-212.

Ribeiro, S. C. et al. Above and belowground biomass in a Brazilian Cerrado. Forest Ecology and Management, v. 262, p. 491-499, 2011. DOI: 10.1016/j.foreco.2011.04.017.

Richards, A. E. et al. The influence of mixed tree plantations on the nutrition of individual species: a review. Tree Physiol, v. 30, p. 1192-208, 2010. DOI: 10.1093/treephys/tpq035.

Rossatto, D. R. et al. Seasonal variation in leaf traits between congeneric savanna and forest trees in Central Brazil: implications for forest expansion into savanna. Trees, v. 27, p. 1139-1150, 2013. DOI: $10.1007 / \mathrm{s} 00468-013-0864-2$.

Sanchez, C. A. Phosphohorus. In: Barker, A. V. \& Pilbeam, D. J. (Ed.). Handbook of plant nutrition. New York: Taylor \& Francis, p. 51-90, 2006.

Santos, A. F. A. et al. Eucalyptus litter capacity of stock and water retention. Floresta e Ambiente, v. 24, p. 1-9. 2017. DOI: 10.1590/2179-8087.030315.

Santos, H. G. dos et al. Sistema brasileiro de classificação de solos. 3. ed. Brasília, DF: Embrapa, 2013. 353 p.

Schumacher, M. V. et al. Produção e decomposição de serapilheira em um povoamento de Eucalyptus urophylla x Eucalyptus globulus maidenii. Revista Cerne, v. 19, n. 3, p. 501-508, 2013. DOI: 10.1590/ S0104-77602013000300018.

Silveira, R. L. V. A. et al. Monitoramento nutricional nos povoamentos de Eucalyptus na região de Bofete e Itatinga pelos métodos do nível crítico e DRIS. Salto: Eucatex, 2002. 30 p. Relatório de pesquisa.

Skorupa, A. L. A. et al. Forest litter decomposition as affected by eucalyptus stand age decomposição de serapilheira florestal. Revista Árvore, v. 39, p. 1055-1064, 2015. DOI: 10.1590/010067622015000600008.

Souza, J. V. et al. Stock and litter decomposition in different vegetation types and eucalypt plantations in the Cerrado region, Brazil. Australian Journal of Basic and Applied Sciences, v. 10, p. 74-81, 2016.
Tang, G. et al. Accelerated nutrient cycling via leaf litter, and not root interaction, increases growth of Eucalyptus in mixed-species plantations with Leucaena. Forest Ecology Management, v. 310, p. 45-53, 2013. DOI: 10.1016/j.foreco.2013.08.021.

Turner, J. \& Lambert, M. Pattern of carbon and nutrient cycling in a small Eucalyptus forest catchment, NSW. Forest Ecology and Management, v. 372, p. 258-268, 2016. DOI: 10.1016/j. foreco.2016.04.012.

Versini, A. et al. The manipulation of organic residues affects tree growth and heterotrophic $\mathrm{CO}_{2}$ efflux in a tropical Eucalyptus plantation. Forest Ecolology Managment, v. 301, p. 79-88, 2013. DOI: 10.1016/j.foreco.2012.07.045.

Viani, R. A. G. et al. Savanna soil fertility limits growth but not survival of tropical forest tree seedlings. Plant Soil, v. 349, p. 341353, 2011. DOI: 10.1007/s11104-011-0879-7.

Vieira, J. A. G. et al. Produção de serapilheira e retorno de nutrientes ao solo pela espécie Eucalyptus urograndis. Revista Brasileira de Agroecologia, v. 4, n. 2, p. 40-43, 2009.

Viera, M. et al. Dinâmica de decomposição e nutrientes em plantio de Eucalyptus Urophylla $\times$ Eucalyptus Globulus no Sul do Brasil. Revista Floresta e Ambiente, v. 20, n. 3, p. 351-360, 2013. DOI: 10.4322/floram.2013.021.

Viera, M. et al. Disponibilização de nutrientes via decomposição da serapilheira foliar em um plantio de Eucalyptus urophylla $x$ Eucalyptus globulus. Revista Floresta e Ambiente, v. 21, n. 2, p. 307-315, 2014. DOI: 10.1590/2179-8087.066313.

Villa, E. B. et al. Aporte de serapilheira e nutrientes em área de restauração florestal com diferentes espaçamentos de plantio. Floresta Ambiente, v. 23, n. 1, p. 90-99, 2016. DOI: 10.1590/21798087.067513.

Vourlitis, G. L. et al. Variations in stand structure and diversity along a soil fertility gradient in a Brazilian savanna (Cerrado) in southern Mato Grosso. Soil Science Society of America, v. 77, p. 1370-1379, 2013. DOI: $10.2136 /$ sssaj2012.0336.

Wolf, B. Improvement in the azometine- $\mathrm{H}^{+}$method for determination of boron. Communication in Soil Science and Plant Analysis, v. 5, p. 39-44, 1974. 
